\title{
ENVELHECER ATUANDO: BEM-ESTAR SUBJETIVO, APOIO SOCIAL E RESILIÊNCIA EM PARTICIPANTES DE GRUPO DE TEATRO
}

\author{
Marineia Crosara de Resende $e^{\star}$ Aline Alves Ferreira $\star \star$

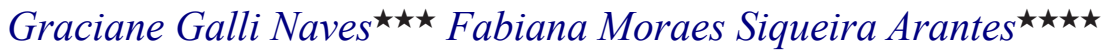 \\ Déborah Ferreira Maria Roldão ${ }^{\star \star \star \star \star ~ K l e b e r ~ G a l a n t e ~ S o u s a ~} a^{\star \star \star \star \star \star}$ \\ Suely Aparecida Moura Abreu
}

\begin{abstract}
Resumo
Essa pesquisa, realizada com participantes do grupo de teatro Os Mais Vividos, objetivou: a) investigar o bem-estar subjetivo; b) averiguar a resiliencia; c) levantar a percepção de suporte social; d) correlacionar bem-estar subjetivo, resiliência e percepção de suporte social. Participaram 12 idosos (idade média 68 anos $\pm 10,57)$. Os Resultados indicaram que os participantes relatam bemestar subjetivo positivo, apresentam níveis de adaptação psicossocial positiva frente a eventos de vida importantes, avaliada pela resiliência e percebem suporte social nos aspectos emocional e prático. As correlações indicaram que quanto maior a idade, maior a resiliência apresentada por idéias de independência e determinação; quanto maior o tempo no grupo, maior a vitalidade; quanto maior a percepção de suporte social, maior o número de afetos positivos experimentados; quanto mais sentimentos positivos apresentam, maior o nivel de satisfação com a vida; a medida que experienciam afetos negativos, tornam-se mais resilientes.
\end{abstract}

Palavras-chave: gerontologia; bem-estar subjetivo; apoio social; resiliência.

^ Psicóloga. Doutora em Educação pela Universidade Estadual de Campinas. Professora Adjunto do Instituto de Psicologia da Universidade Federal de Uberlândia. Endereço: Universidade Federal de Uberlândia, Instituto de Psicologia. Av. Pará, 1720 - Campus Umuarama. Uberlandia, MG - Brasil. CEP: 38405-382.

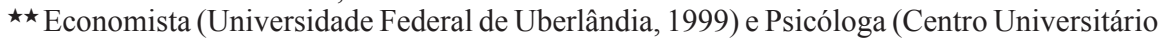
do Triângulo, UNITR, 2008) exercendo atividade na área clinica em consultório particular e no CREAS (Centro de Referência Especializado em Assistência Social) da Prefeitura Municipal de Jaboticabal/SP.

$\star \star \star$ Psicóloga pelo Centro Universitário do Triângulo

$\star \star \star \star$ Psicóloga Clínica e Social do Centro Evangélico de Reabilitação e Trabalho Orientado de Uberlândia - CERTO.

$\star \star \star \star \star$ Psicóloga pelo Centro Universitário do Triângulo

$\star \star \star \star \star \star$ Psicólogo residente, área de concentração em oncologia - Programa de Residência Multiprofissional do Hospital das Clínicas da Universidade Federal de Uberlândia.

$\star \star \star \star \star \star \star$ Psicóloga pelo Centro Universitário do Triângulo. Especialista em Psicologia Transpessoal e Humanista, pela Universidade Metropolitana de Belo Horizonte.

E-mail: moura_jf@yahoo.com.br 


\title{
To AGE ACTING: SUBJECTIVE WELL-BEING, SOCIAL SUPPORT AND RESILIENCE IN A THEATER GROUP'S PARTICIPANTS
}

\begin{abstract}
This study, carried out with a theater group's participants, aimed: a) to investigate subjective well-being; b) to identify the resilience; c) to evaluate social support perception; d) to correlate the psychological variables: subjective well-being, resilience, and social support perception. Methods: Participants: 12 elderly (mean age 68 years \pm 10.57 ). Results: The participants presented positive subjective well-being, they indicated positive levels of psychosocial adaptation, evaluated by resilience and they had told to perceive social support in the following aspects: emotional and practical. The correlations indicated that the most aged had higher resilience; higher the time participation in the group, higher vitality; higher perception of social support, higher the positive affect; the ones who presented more positive feelings, have higher level of life satisfaction; by the time they experiment more negative affect they become more resilient.
\end{abstract}

Keywords: gerontology; subjective well-being; social support; resilience.

\section{INTRODUÇÃo}

O envelhecer sempre trouxe inquietações ao homem, ao mesmo tempo em que lhe despertou para o valor de uma vida longeva e prazerosa. Nos últimos anos, a velhice se tornou uma questão social muito discutida e pesquisada em diversos países do mundo. Considerando as técnicas preventivas de tratamento das doenças, o tempo de vida das pessoas tem aumentado consideravelmente (ARAÚJO; CARVALHO, 2004; VERAS, 2009) e essa nova realidade traz ao convívio social um maior número de pessoas longevas e que esperam viver bem, com qualidade de vida e bem-estar subjetivo.

O bem-estar subjetivo é um construto referente à avaliação que a própria pessoa faz sobre sua vida e, avaliações assim, podem ser feitas mediante um componente cognitivo como julgamentos sobre a satisfação com a vida como um todo ou referenciada a domínios específicos, ou mediante um componente afetivo no qual estão incluídos estados agradáveis e desagradáveis e a busca de equilíbrio entre eles. Neste domínio está refletido a avaliação que o indivíduo faz dos domínios anteriores. O âmbito do bem-estar subjetivo tem interessado bastante os psicólogos e segundo Diener (2000) é uma das áreas de análise da Psicologia Positiva, que tem vivenciado uma enorme ascensão nos últimos tempos.

O bem-estar subjetivo cobre assuntos que utilizam vários termos, tais como: felicidade, satisfação, estado de espírito, além de estar incluído no universo mais amplo no conceito de qualidade de vida (FIQUER, 2006). Diener 
(2000) afirma que pesquisas no mundo indicam que a felicidade e a satisfação com a vida são muito importantes para se viver bem e que os indivíduos pensam a respeito delas freqüentemente.

A satisfação com a vida é um dos indicadores de bem-estar, geralmente definido como se tendo uma boa vida e sendo feliz (DIENER, 2000). Enquanto subjetiva, a avaliação da satisfação com a vida reflete as expressões de cada pessoa quanto a seus próprios critérios de satisfação como um todo e em domínios específicos, como saúde, trabalho, condições de moradia, relações sociais e outros. Assim, reflete o bem-estar individual, ou seja, o modo e os motivos que levam as pessoas a viverem suas experiências de vida de maneira positiva (DIOGO, 2003). Segundo Freire (2000), a vida pode ser satisfatória, especialmente quando há disposição para enfrentar os desafios da vida, lutar pelos direitos dos cidadãos e colocar em prática projetos viáveis dentro das condições pessoais e do meio ambiente em que se vive, particularmente quando a pessoa conta com uma rede de suporte social.

O bem-estar subjetivo pertence ao âmbito da experiência privada. Suas medidas incluem tanto avaliação global, quanto avaliações particulares referenciadas a domínios, tais como saúde física e cognitiva, relações sociais, relações familiares e espiritualidade. Estes aspectos podem ser medidos tanto sob um enfoque cognitivo quanto emocional (NERI, 2001), são considerados componentes emocionais do bem-estar subjetivo, o afeto positivo e o afeto negativo.

$\mathrm{O}$ afeto positivo reflete a extensão em que a pessoa sente-se entusiasmada, ativa e alerta e pode ser subdividido em emoções específicas como alegria, afeição e orgulho. Afeto positivo tem sido referido como um fator de proteção frente a situações de estresse, uma vez que pessoas que mantêm estados emocionais positivos experienciam menos problemas físicos. Já o afeto negativo reflete o quanto o sujeito sente-se angustiado e pouco motivado e subdivide-se em emoções como vergonha, culpa, tristeza, raiva e ansiedade (ARTECHE, 2003).

Outro indicador de bem-estar é a vitalidade subjetiva, cuja definição se refere ao estado de sentir-se vivo e alerta e ter energia para si (CHAVES, 2003). Esse conceito deve ser compreendido como um componente vital que faz parte do pleno funcionamento do indivíduo e inclui algo mais que senso de bem-estar, englobando sentir amor, ser eficiente, ter algo a realizar (RYAN; FREDERICK, 1997).

Acredita-se que pessoas com maior nível de bem-estar subjetivo são indivíduos mais resilientes, ou seja, apresentam maior capacidade para enfrentar as adversidades, transformando-se e superando-as (SILVA et al., 2003). Polleto (2007, p. 17), a partir de ampla revisão de literatura, relata que resiliência é um conceito originário da Física, que foi definido como "a capacidade de um material absorver energia sem sofrer deformação plástica". Em Psicologia, a definição de resiliência não é tão clara e precisa quanto na Física, mas seu conceito tem o caráter de possibilitar a superação das adversidades. Yunes (2003) afirma que, para os seres humanos não é possível absorver um evento estressor e voltar à forma anterior. Quando uma pessoa passa por uma adversidade, ela aprende, cresce, desenvolve e amadurece (POLETTO, 2007). 
Resiliência aparece então definida como a habilidade que o indivíduo tem para reconhecer a dor, perceber seu sentido, e tolerá-la até resolver os conflitos de forma construtiva (PINHEIRO, 2004). Pode-se traduzir a resiliência como sendo a capacidade de responder de forma mais consistente aos desafios e dificuldades; reagir com flexibilidade e capacidade de recuperação diante das circunstâncias desfavoráveis, apresentando diante disso, uma atitude otimista, positiva e perseverante; manter um equilíbrio dinâmico durante e após as dificuldades pode ser uma característica de personalidade que possibilita ao sujeito superar-se às pressões de seu mundo (YUNES; SZYMANSKI, 2001).

Segundo Laranjeira (2007), a resiliência representa um traço de caráter como também um modo de funcionamento psíquico ou comportamental do indivíduo, de modo que este apresenta uma habilidade adaptativa perante as diversas situações (biológicas e sociopsicológicas) que requerem a utilização de capacidades intrapsíquicas (internas) como ligadas ao meio social e afetivo (externas), que possibilita a junção de um psiquismo construído de modo a adequar-se à inserção social. Rutter (1987 apud OLIVEIRA, 2007) menciona que a resiliência é um processo individual, cada pessoa desenvolve sua forma de lidar com as dificuldades surgidas ao longo da vida, sendo assim, alguns podem lidar satisfatoriamente quando em situação estressante enquanto outros dão uma resposta negativa àquela situação, isso não significa que a pessoa resiliente dará sempre respostas satisfatórias.

Todos os seres humanos, em algum momento da vida, enfrentam situações impactantes, que podem ser no domínio físico, afetivo e/ou psicológico. A diferença está em como as pessoas ativam sua capacidade e desenvoltura para lidar com essas situações (SILVA et al., 2003). A identificação destes processos e sua melhor compreensão possibilitam a formulação de estratégias a fim de promover a resiliência e melhor qualidade de vida, particularmente na velhice.

As concepções estereotipadas, ainda veiculadas pela mídia, da idade adulta avançada e velhice têm levado a vê-las como um tempo marcado por pouca capacidade de resiliência. Contudo, pesquisadores como Ryff (1989), Diener e Suh (1998), Freire (2001), Caprara e Steca (2005), Karoly e Ruehlman (2006), Laranjeira (2007) têm apontado a resiliência como sendo um componente importante do envelhecimento psicológico não apenas como fenômeno de ocorrência natural (isto é, os adultos mais velhos espontaneamente mostram um funcionamento resiliente a despeito da presença de riscos), mas como característica que pode ser promovida por intervenções favoráveis provenientes do ambiente (FREIRE, 2001), particularmente através de redes sociais.

As redes sociais são definidas como "teias" de relações sociais que circundam o indivíduo bem como suas características (por exemplo, disponibilidade e freqüência de contato com amigos e parentes), ou com grupos de pessoas com quem há contato ou alguma forma de participação social (por exemplo, grupos religiosos, associações sindicais) (ANDRADE, 2001). Griep, Chor e Faerstein (2003) afirmam que apoio social refere-se a um sistema de relações formais e informais pelo qual os indivíduos recebem ajuda emocional, material e/ou de informação para enfrentarem situações geradoras de tensão emocional. 
Trata-se de um processo recíproco que gera efeitos positivos tanto para o sujeito que recebe como também para quem oferece o apoio, permitindo que ambos tenham mais sentido de controle sobre suas vidas. Desse processo se aprende que as pessoas necessitam umas das outras.

$\mathrm{O}$ apoio social que as redes proporcionam remete ao dispositivo de ajuda mútua, potencializado quando uma rede social é forte e integrada. Referirse ao apoio social, fornecido pelas redes, é ressaltar os aspectos positivos das relações sociais, como o compartilhar informações, o auxílio em momentos de crise e a presença em eventos sociais. Um envolvimento comunitário, por exemplo, pode ser significativo no aumento da confiança pessoal, da satisfação com a vida e na capacidade de enfrentar problemas (MINKLER, 1985 apud ANDRADE; VAITSMAN, 2002).

As redes de relações podem ser categorizadas de diferentes formas, seja de acordo com a estrutura, natureza das relações, interações proporcionadas, ou mesmo, pelo grau de desejo investido sobre tais relações. Siqueira (2008), a partir de revisão de literatura, afirma que existem diferentes tipos de apoio que alguém pode receber da rede social, sendo três os mais amplamente estudados: suporte emocional, suporte instrumental e suporte informacional. O primeiro refere-se ao que as pessoas fazem ou dizem a alguém (dar conselhos, ouvir seus problemas, mostrar-se empático e confiável) e são percebidos como expressões de carinho, cuidados e preocupação do outro. $\mathrm{O}$ suporte instrumental compreende as ajudas tangíveis ou práticas que outros (pessoas ou instituições) podem prover a alguém (cuidados com crianças, provisões de transporte, empréstimos de dinheiro ou ajudas com tarefas diárias). Por último, o suporte informacional inclui receber de outras pessoas noções indispensáveis para que o indivíduo possa guiar e orientar suas ações ao dar solução a um problema ou no momento de tomar uma decisão.

Os recursos disponibilizados pela rede social e categorizados por Rodriguez e Cohen (1998) nos três tipos apresentados acima poderiam constituir duas categorias de suporte: um de cunho eminentemente afetivo - o suporte emocional -, porque se origina de ações que demonstram afabilidade, afeição e carinho por parte de alguém a outrem durante relações sociais. Os outros dois tipos - instrumental e informacional-, reúnem doações com caráter utilitário, objetivo e prático. Portanto, segundo Siqueira (2008), suporte emocional reuniria os apoios que levam o indivíduo a acreditar que é possível encontrar, entre as pessoas de sua rede social, alento para reagir e superar os possíveis transtornos no âmbito afetivo, ou para dividir e compartilhar as alegrias advindas de suas realizações, conquistas e sucessos pessoais. Suporte prático, por seu turno, representa segurança e tranqüilidade para o indivíduo ao acreditar que existam, entre os integrantes de sua rede social, pessoas com disposição para suprir alguma necessidade de ordem prática.

Dentro da rede social dos idosos, a família tem sido apontada como sendo a fonte primária de suporte e que, juntamente com os vizinhos e amigos, formam uma rede informal (RESENDE et al., 2007). Segundo Carmona e Melo (2000 apud CARNEIRO et. al., 2007), desenvolver redes sociais de apoio através de uma conduta interpessoal efetiva, constitui um dos fatores mais im- 
portantes para se precaver e recuperar dos transtornos relativos à saúde mental. Acrescenta-se ainda que a construção de redes sociais aumenta a freqüência de contato e os intercâmbios sociais, porém, é a natureza desse intercâmbio, ou seja, as funções do apoio como os aspectos subjetivos envolvidos que resultam uma melhora e proteção da saúde (GUEDEA et al., 2006).

Quando baseados na reciprocidade e solidariedade, as relações sociais podem proporcionar confiança, ajuda convencional, influenciar o bem-estar global, a saúde psíquica e física das pessoas (NOGUEIRA, 2001). Os contatos sociais permitem engajamento social, que também é uma forma de se vivenciar o desenvolvimento na idade adulta, de maneira bem sucedida.

O apoio social deve ser compreendido como uma experiência pessoal e subjetiva que leva a um maior senso de satisfação com a vida. Silva et al. (2003) sugerem a existência de uma relação entre apoio social e uma variedade de medidas dependentes: saúde, adaptação psicológica, percepção de bem-estar, redução do mal estar, longevidade e mortalidade, satisfação com a vida, entre outros. Trata-se de um conceito multidimensional que se refere aos recursos materiais e também psicológicos aos quais as pessoas têm acesso através de suas redes sociais. $\mathrm{O}$ apoio social advindo da família e dos amigos pode amenizar os efeitos do estresse na vida do idoso e é manifestado na forma de amor, preocupação, afeição e assistência (RAMOS, 2002).

A interação e as atividades de grupos com pessoas da própria geração e com experiências semelhantes favorecem o bem-estar do indivíduo, trazendo como conseqüência a construção de significados comuns, a maior troca de experiências e contatos sociais (RESENDE; RABELO, 2004), como acontece nos grupos para a terceira idade, como por exemplo, o grupo Os Mais Vividos do SESC em Uberlândia-MG. Que congrega pessoas acima de 50 anos, têm entre suas atividades ensaios e apresentação de peças de teatro e dança para a comunidade.

Considerando a experiência dos idosos em um grupo de teatro, os impactos e transformações advindas dessa experiência, esse trabalho tem como objetivos: a) Investigar o bem-estar subjetivo de idosos engajados com o teatro; b) Averiguar a resiliência destes idosos; c) Analisar a percepção de suporte social destes idosos; d) Correlacionar bem-estar subjetivo, resiliência e suporte social.

\section{Método}

\section{Participantes:}

Participaram dessa pesquisa 12 idosos (média de idade 68 anos $\pm 10,57$ ), participantes do grupo Os Mais Vividos do SESC em Uberlândia-MG, a maioria do sexo feminino $(91,67 \%)$, morando sozinhos $(50,00 \%)$ e responsáveis pelo próprio sustento $(58,33 \%)$. As características sóciodemográficas podem ser vistas na Tabela 1. 
Envelhecer atuando: bem-estar subjetivo, apoio social e resiliência em participantes de grupo de teatro

Tab. 1 - Distribuição da freqüência de características sóciodemográficas dos Sujeitos

\begin{tabular}{|c|c|c|c|}
\hline Variáveis & & $\mathbf{N}$ & $\%$ \\
\hline \multirow[t]{2}{*}{ Sexo } & Femin ino & 11 & 91,67 \\
\hline & Masculino & 1 & 8,33 \\
\hline \multirow[t]{4}{*}{ Idade } & $<60$ & 3 & 25,00 \\
\hline & $60-69$ & 4 & 33,33 \\
\hline & $70-79$ & 1 & 8,33 \\
\hline & $>=80$ & 4 & 33,33 \\
\hline \multirow[t]{4}{*}{ Estado Civil } & Casado & 2 & 16,67 \\
\hline & Solteiro & 4 & 33,33 \\
\hline & Viúvo & 4 & 33,33 \\
\hline & Separado & 2 & 16,67 \\
\hline \multirow[t]{4}{*}{ Escolaridade } & Ensino Básico & 5 & 41,67 \\
\hline & Ensino Fundamental & 1 & 8,33 \\
\hline & Ensino Médio & 5 & 41,67 \\
\hline & Pós-Graduação & 1 & 8,33 \\
\hline \multirow[t]{2}{*}{ Trabalha } & $\operatorname{Sim}$ & 8 & 66,67 \\
\hline & Não & 4 & 33,33 \\
\hline \multirow[t]{2}{*}{ Tem filhos } & Sim & 11 & 91,67 \\
\hline & Não & 1 & 8,33 \\
\hline \multirow[t]{6}{*}{$\mathrm{N}^{o}$ de Filhos } & 1 & 1 & 10,00 \\
\hline & 2 & 2 & 20,00 \\
\hline & 3 & 3 & 30,00 \\
\hline & 4 & 2 & 20,00 \\
\hline & 5 & 1 & 10,00 \\
\hline & 6 & 1 & 10,00 \\
\hline \multirow[t]{4}{*}{ Com quem mora } & Sozinho & 6 & 50,00 \\
\hline & Cônjuge & 2 & 16,67 \\
\hline & Filhos & 3 & 25,00 \\
\hline & Cônjuge/Filhos/Netos & 1 & 8,33 \\
\hline Responsável pelo & Sim & 7 & 58,33 \\
\hline sustento & Não & 5 & 41,67 \\
\hline
\end{tabular}

Fractal: Revista de Psicologia, v. 22 - n. 3, p. 591-608, Set./Dez. 2010 


\section{Instrumentos}

a) Ficha de Informações sócio-demográficas - Questionário para coleta de dados sobre idade, gênero, renda mensal, profissão, ocupação, estado civil e tipo de arranjo domiciliar.

b) Medida de bem-estar subjetivo: composto pelos seguintes instrumentos:

b.1) Escala de Vitalidade (CHAVES, 2003): avalia o grau em que o participante tem se sentido em termos de vigor físico, mental e alerta, nos últimos dias. Compõe-se de sete itens (por exemplo, tenho energia e disposição; sinto-me vivo e cheio de vitalidade), cujas respostas devem ser dadas em uma escala de sete pontos, indo de $\mathbf{1}=$ "Nada Verdadeiro" a $\mathbf{7}=$ "Totalmente Verdadeiro" $(\alpha=0,634)$.

b.2) Escala de Afetos Positivos e Negativos (CHAVES, 2003): formada por nove adjetivos, sendo 5 positivos e 5 negativos. Os afetos positivos são: feliz, alegre, satisfeito, divertido e otimista; e os negativos são: deprimido, preocupado, frustrado, raivoso e infeliz. O instrumento avalia quanto o participante tem experienciado cada uma dessas emoções nos últimos dias. Os itens são respondidos numa escala de sete pontos, variando de $\mathbf{1}=$ "Nada" a 7 = "Extremamente" (Afetos Positivos $\alpha=0,876$; Afetos Negativos $(\alpha=0,653)$.

b.3) Escala de Satisfação com a Vida (CHAVES, 2003): compõe-se de cinco itens (por exemplo, estou satisfeito com minha vida; as condições da minha vida são excelentes), respondidos em escala tipo Likert, indo de $\mathbf{1}=$ "Discordo Totalmente" a 7 = "Concordo Totalmente" $(\alpha=0,810)$.

c) Escala de Resiliência (PESCE et al., 2004) $(\alpha=0,816)$ : mede níveis de adaptação psicossocial positiva frente a eventos de vida importantes, divididos em três fatores: "Fator 1 " $(\alpha=0,842)$ : indica resoluções de ações e valores (que dão sentido à vida como: amizade, realização pessoal, satisfação e significado da vida); "Fator 2" ( $\alpha=0,052$ : indica idéias de independência e determinação; "Fator 3" $(\alpha=0,510)$ : indica auto-confiança e capacidade de adaptação à situação. Possui 25 itens descritos de forma positiva com resposta tipo Likert variando de 1 (discordo totalmente) a 7 (concordo totalmente).

d) Escala de Percepção de Suporte Social (SIQUEIRA, 2008) $(\alpha=0,954)$ - contém 29 itens, divididos em 2 dimensões: "Suporte prático" $(\alpha=0,911)$, com 19 itens, que engloba suporte instrumental, ou seja, a percepção da possibilidade de doação de recursos objetivos e tangíveis pela rede social, que incluem o empréstimo ou fornecimento de bens materiais e suporte informacional, a percepção da possibilidade de doação de recursos de aclaramento pela rede social, que incluem sugestões, orientações ou esclarecimentos e "Suporte emocional" $(\alpha=0,923)$, com 10 itens, avalia a percepção da possibilidade de doação de recursos afetivos pela rede social, que incluem compreensão, atenção e preocupação. As respostas devem 
ser dadas numa escala de quatro pontos $(1=$ nunca; $2=$ poucas vezes; $3=$ muitas vezes; $4=$ sempre) com a qual os participantes informaram a freqüência com que percebem a possibilidade de poder contar com o apoio de alguém.

\section{Procedimentos}

a) Para a coleta de dados: Seguindo a Resolução 196/96 do Conselho Nacional de Saúde, este projeto foi submetido à apreciação e aprovado pelo Comitê de Ética em Pesquisa da Universidade Federal de Uberlândia-MG, sendo aprovado em parecer $n^{\circ}$. 124/07. Após a aprovação do projeto de pesquisa pelo Comitê de Ética em Pesquisa, foi feito contato com o responsável pelo grupo Os Mais Vividos, solicitando autorização para a realização da pesquisa. Posteriormente foram contactados os participantes deste grupo em dias de atividades, para explicar os objetivos da pesquisa, convidá-los para participar, esclarecer sobre o caráter voluntário da participação e a garantia de sigilo dos dados individuais e agendar data e local para a coleta de dados. A aplicação dos instrumentos foi feita individualmente em entrevista na própria instituição. Antes, cada sujeito foi convidado a ler e a assinar o Termo de Consentimento Livre e Esclarecido.

b) Para a análise de dados: Para descrever o perfil da amostra segundo as variáveis em estudo, foram feitas tabelas de freqüência das variáveis categóricas através dos valores de freqüência absoluta (n) e relativa (\%), e estatísticas descritivas (com medidas de posição e dispersão - média, desvio-padrão, valores mínimo, máximo, mediana e quartis) das variáveis contínuas. Para análise da consistência interna das escalas foi utilizado o coeficiente alfa de Cronbach, em todas as escalas. Valores alfa acima de 0,70 indicam boa consistência interna. Para analisar a correlação entre as variáveis numéricas (escores das escalas) foi utilizado o coeficiente de correlação de Spearman. O nível de significância adotado para os testes estatísticos foi de $5 \%(\mathrm{p}<0,05)$.

\section{Resultados}

\section{Bem-estar subjetivo}

Os participantes dessa pesquisa relatam bem-estar subjetivo positivo indicado por satisfação com a vida (média 5,$95 ; \mathrm{DP}=0,94$ ), afetos positivos (média 5,83; $\mathrm{DP}=1,05$ ), afetos negativos (média 2,65; $\mathrm{DP}=1,01$ ) e vitalidade (média 6,$12 ; \mathrm{DP}=0,64$ ).

\section{Resiliência}

Os idosos indicaram níveis de adaptação psicossocial positiva frente a eventos de vida importantes, avaliada pela resiliência (média 6,09; $\mathrm{DP}=0,44$ ), sendo no "Fator 1" (média 6,47; DP=0,49), que indica resoluções de ações e valores (que dão sentido à vida como: amizade, realização pessoal, satisfação 
e significado da vida), "Fator 2" (média 5,36; DP=0,71), indica idéias de independência e determinação; "Fator 3" (média 5,88; DP=1,07), indicando autoconfiança e capacidade de adaptação à situação.

\section{Percepção de Suporte Social}

Com relação à percepção de suporte social, os participantes relataram perceber suporte social nos aspectos: suporte emocional (média 3,19; $\mathrm{DP}=0,79$ ) e suporte prático (média 2,$73 ; \mathrm{DP}=0,74$ ).

\section{Correlações entre as variáveis}

A partir da correlação de Spearman verificou-se que:

Houve correlação significativa do Fator 2 de resiliência com a idade $(\mathrm{r}=0,62527 ; \mathrm{p}=0,0297)$, ou seja, quanto maior a idade, maior o grau de resiliência apresentado por idéias de independência e determinação.

Houve correlação significativa entre o tempo de participação no grupo e vitalidade $(\mathrm{r}=0,73800 ; \mathrm{p}=0,0061)$, ou seja, quanto maior o tempo no grupo, maior a vitalidade.

Houve correlação significativa entre afetos positivos e suporte social $(\mathrm{r}=0,71365 ; \mathrm{p}=0,0088)$, ou seja, quanto maior a percepção de suporte social, maior o número de afetos positivos experimentados.

Houve também correlação significativa entre os escores positivos e negativos com satisfação com a vida e resiliência, quanto maior o escore de afetos positivos, maior o escore de satisfação com a vida $(r=0,65709 ; \mathrm{p}=0,0208)$ e quanto maior o escore de afetos negativos, maior o escore do Fator 2 de resiliência $(\mathrm{r}=0,62008 ; \mathrm{p}=0,0315)$, ou seja, quanto mais sentimentos positivos apresentam, maior o nível de satisfação com a vida, como também quanto mais experienciam afetos negativos, tornam-se cada vez mais resilientes.

\section{Discussão}

Este estudo investigou o bem-estar subjetivo, a resiliência, a percepção de suporte social de idosos que participam de um grupo de teatro, bem como a associação entre as variáveis citadas. Os estudos sobre o bem-estar subjetivo contribuem para a compreensão do ser humano, tendo como foco suas potencialidades e não suas vulnerabilidades (PASSARELI; SILVA, 2007).

Os participantes dessa pesquisa relatam bem-estar subjetivo positivo indicado por satisfação com a vida, afetos positivos e vitalidade. Segundo Guedea et al. (2006), o bem-estar subjetivo está relacionado a um envelhecimento mais saudável, além de ser um indicador de saúde mental, têm sido descrito como sinônimo de felicidade, ajuste e integração social, aspectos esses presentes no grupo Os Mais Vividos. Diener et al. (1999) relatam que as pesquisas têm indicado que a satisfação com a vida não diminui com a idade, apesar do declínio associado à idade em recursos como saúde, situação conjugal e renda, mas que a intensidade 
das experiências afetivas diminui ao longo do envelhecimento. Segundo Diener e Suh (1998), os idosos tendem a se descrever como mais satisfeitos do que os jovens. Esta diferença pode ocorrer porque as novas gerações são sempre mais exigentes do que as anteriores, o que resulta em discrepância nas avaliações que os mais jovens e os mais velhos fazem de sua satisfação com a vida (FREIRE, 2000). No caso das pessoas do grupo investigado, mesmo não tendo sido objeto de investigação desse estudo, pode-se inferir que a satisfação está relacionada à autonomia, porque dão conta da própria vida, moram sozinhas, são responsáveis pelo próprio sustento, ou seja, ativaram recursos para compensar as perdas relacionadas ao envelhecimento e manterem-se ativos e engajados socialmente.

Joia, Ruiz e Donalisio (2007) em pesquisa com 365 idosos no município de Botucatu-SP, descreveram que a maioria dos idosos estava satisfeita com sua vida em geral e em aspectos específicos, sendo que indicaram que o grau de satisfação com a vida estava associado à: conforto domiciliar; valorizar o lazer como qualidade de vida; acordar bem pela manhã; não referir solidão; fazer três ou mais refeições diárias e referência de não possuir Diabetes Mellitus. Os autores relatam ainda que a pesquisa de Xavier el al. (2003) obtiveram resultados semelhantes na cidade de Veranópolis (RS), onde $57,0 \%$ da população idosa estudada referiram valores significativos de satisfação com a vida. Assim como nessa pesquisa, a satisfação com a vida está associada à valorização do lazer como qualidade de vida, os participantes, mesmo os que ainda trabalham, que é a maioria, levam a vida de maneira a incorporar a atividade de dança e teatro como um aspecto relevante para a manutenção da saúde e bem-estar.

Resende et al. (2006), em pesquisa com 90 pessoas com idade entre 25 e 85 anos, encontraram que os participantes apresentaram elevado grau de satisfação com a vida e expectativa positiva com relação à vida futura. As pessoas que apresentam maior satisfação com a vida foram as que recebiam mais suporte afetivo, ou seja, parece que participar do grupo Os Mais Vividos proporciona aos seus integrantes sentimentos de compreensão, atenção e companheirismo. O apoio social é considerado capaz de gerar efeitos benéficos tanto para a saúde física como mental, guardando uma estreita relação com bem-estar (RODRIGUEZ; COHEN, 1998).

Com relação à percepção de suporte social, os participantes relataram perceber suporte social nos aspectos: suporte emocional e suporte prático. Quando os membros sociais da rede de relações fornecem auxílio, estão dando muito mais que meramente oferecer suporte emocional e informativo. As pessoas mais velhas envolvidas no processo sentem-se estimadas e valorizadas, o que as ajuda a perceber que têm um lugar no jogo da ordem social mais ampla (KRAUSE, 2007). Receber suporte auxilia as pessoas mais velhas a ter senso de pertença, a sentirem-se parte do grupo, identificando-se com o mesmo, encontrando motivação; traz senso de propósito e significado na vida, como no grupo pesquisado. Os achados desse estudo corroboram a afirmação de Freire e Resende (2001), quando dizem que a busca e a realização do sentido pessoal representam uma nova perspectiva de promoção de bem-estar, de enfrentamento e de adaptação, porque possibilita ao indivíduo experimentar uma continuidade no crescimento pessoal, mesmo vivendo as perdas e o declínio físico associados ao envelhecimento. 
Os idosos participantes desse estudo indicaram níveis de adaptação psicossocial positiva frente a eventos de vida importantes, avaliados pela resiliência, no aspecto de resoluções de ações e valores (que dão sentido à vida como: amizade, realização pessoal, satisfação e significado da vida), através de idéias de independência e determinação; auto-confiança e capacidade de adaptação à situação. Karoly e Ruehlman (2006) investigando a correlação entre dor crônica e resiliência, afirmam que pessoas resilientes relatam mais atitudes positivas frente ao futuro, maior percepção de controle e auto-confiança. Sirois, Davis e Morgan (2006) descrevem que as crenças de controle têm um papel central na vida do indivíduo. Manter um senso de controle pode ajudar a compensar os sentimentos de desamparo e angústia trazidos por situações adversas. A crença de que a pessoa é capaz de administrar o mundo externo para atender as suas necessidades, pode influenciar suas expectativas.

Bauer, McAdams e Sakaeda (2005) dizem que adultos mais velhos têm mais probabilidade de relatarem estar vivendo uma boa vida do que adultos mais jovens, e que este fato seria parcialmente explicado em função de que as pessoas mais velhas interpretam seu passado em termos de crescimento. Os dados dessa pesquisa mostraram que quanto maior a idade, maior o grau de resiliência apresentado por idéias de independência e determinação. Na velhice, as pessoas dispõem de maior maturidade, tempo e experiência existencial para tornarem-se agentes que movimentam uma rede de solidariedade, oposta ao modelo produtivista e impessoal da sociedade contemporânea, podendo despertar atitudes e valores de maior tolerância e solidariedade nos mais jovens. Neste intercâmbio, a comunidade pode substituir a existência de identidades isoladas para a consolidação social de cumplicidade e consciência de pertencimento (GOMES, LESSA; SÁ, 2006-2007).

Para Mella et al. (2004), o bem-estar subjetivo é determinado pelo grau de apoio que o indivíduo sente que tem por parte de sua rede de relações, pelo gênero e pela ausência de sintomas depressivos. Os autores citam Scott e Roberto (1985 apud MELLA et al., 2004), para quem a maior integração entre a rede de apoio está associada com menores problemas de saúde física e mental, menor incidência de hospitalizações e admissões psiquiátricas e melhores resultados no enfrentamento de eventos estressantes. Ter uma rede de apoio influencia a manutenção de uma auto-imagem positiva e elevada auto-estima, aspectos centrais do bem-estar subjetivo. Talvez por isso, os resultados dessa pesquisa indicaram que quanto maior a percepção de suporte social, maior o número de afetos positivos experimentados. O apoio social é uma variável importante, facilitadora de resultados positivos para o bem-estar subjetivo. Indivíduos que têm altos níveis de apoio social e estão satisfeitos com a qualidade de sua rede de relações têm maior senso de bem-estar (CAPRARA; STECA, 2005).

As convicções de pessoas na própria capacidade para administrar produtivamente suas relações com os outros melhoram a visão positiva que elas têm sobre elas mesmas, sua vida e o futuro, como também a prevalência de afetos positivos sobre os negativos nas experiências diárias (CAPRARA; STECA, 2005). Essa afirmação corrobora os dados encontrados nessa pesquisa, que quanto mais sentimentos positivos apresentam, maior o nível de satisfação com a vida. 
Outro resultado interessante, encontrado nesse estudo, foi que quanto mais os participantes experienciam afetos negativos, tornam-se cada vez mais resilientes. De acordo com Oaksford, Frude e Cuddihy (2005), há evidência crescente de que eventos estressantes nem sempre terminam em resultados negativos e de que algumas pessoas se tornam mais fortes ou crescem psicologicamente porque passaram por situações em que precisaram enfrentar eventos estressantes. Para Cowan, Cowan e Schulz (1996 apud OLIVEIRA, 2007), a resiliência está relacionada ao fato de que a pessoa que desenvolve esta capacidade na vida, poderá alcançar resultados mais positivos, o que não significa a evitação de riscos, mas o bom enfrentamento e adaptação as adversidades.

\section{Considerações Finais}

A relação entre bem-estar subjetivo, apoio social e resiliência é bastante complexa (GALLAGHER; VELLA-BRODRICK, 2008), por isso a necessidade de se investigar mais sobre essas variáveis no processo de envelhecimento. Estudos comparativos, entre idosos engajados socialmente, como os participantes dessa pesquisa, com idosos menos ativos, ou mesmo residentes em instituições de longa permanência poderiam trazer novas contribuições para a compreensão das variáveis estudadas.

É importante ressaltar uma das limitações desse estudo, que foi a escolha de um grupo específico como Os Mais Vividos, pois engloba um pequeno número de participantes. Embora não exista consenso com relação ao número mínimo para realização de algumas análises, um número maior traria análises mais fidedignas.

\section{REFERÊNCIAS}

ANDRADE, G. R. B. Grupo de apoio social no hospital: o caso do lutando para viver. 2001. Dissertação (Mestrado em Saúde Pública)-Fundação Osvaldo Cruz, Rio de Janeiro, 2001.

ANDRADE, G. R. B.; VAITSMAN, J. Apoio Social e redes: conectando solidariedade e saúde. Ciências e Saúde Coletiva, Rio de Janeiro, v. 7, n. 4, p. 925-934, 2002.

ARAÚJO, L. F.; CARVALHO, V. A. M. L. Aspectos sócio-históricos e psicológicos da velhice. Revista de Humanidades, v. 6, n. 13, p. 1-3, 2004.

ARTECHE, A. X. O impacto do trabalho nas variáveis coping e bem-estar subjetivo em uma amostra de adolescentes. 2003. Dissertação (Mestrado em Psicologia) - Instituto de Psicologia, UFRGS, Porto Alegre, 2003.

BAUER, J. J.; McADAMS, D. P.; SAKAEDA, A. R. Interpreting the good life: growth memories in the lives of mature, happy people. Journal of Personality and Social Psychology, [S.1.], v. 88, n. 1, p. 203-217, 2005. 
CAPRARA, G. V.; STECA, P. Affective and social self-regulatory efficacy beliefs as determinants of positive thinking and happiness. European Psychologist, [S.1.], v. 10, n. 4, p. 275-286, 2005.

CARNEIRO, R. S. et al. Qualidade de vida, apoio social e depressão em idosos: relação com habilidades sociais. Psicologia: Reflexão e Crítica, Porto Alegre, v. 20, p. 229-237, 2007.

CHAVES, S. S. S. Valores como preditores do bem-estar subjetivo. 2003. Dissertação (Mestrado em Psicologia)-Universidade Federal da Paraíba, João Pessoa, 2003.

DIENER, E. Subjective well-being: the science of happiness and a proposal for a national index. American Psychologist, v. 55, n. 1, p. 34-43, jan. 2000.

DIENER, E.; SUH, M. E. Subjective well-being and old age: an international analysis. In: SCHAIE, K. W.; LAWTON, M. P. (Ed.). Focus on Emotion and Adult Development. New York: Springer, 1998. p. 304-324. Annual Review of Gerontology and Geriatrics, v. 17.

DIENER, E. et al. Subjective well-being: three decades of progress. Psychological Bulletin, [S.1.], v. 125, p. 276-302, 1999.

DIOGO, M. J. D. E. Satisfação global com a vida e determinados domínios entre idosos com amputação de membros inferiores. Revista Panamericana de Saúde Pública, v. 13, n. 6 , p. 395-400, 2003.

FIQUER, J. T. Bem-estar subjetivo influência de variáveis pessoais e situacionais em auto-relato de afetos positivos. 2006. Dissertação. (Mestrado em Psicologia Experimental) - Instituto de Psicologia, USP, São Paulo, 2006.

FREIRE, S. A. Bem-estar subjetivo e metas de vida: comparação entre três grupos etários. 2001. Tese (Doutorado em Educação)-Faculdade de Educação, UNICAMP, Campinas, SP, 2001.

FREIRE, S. A. Envelhecimento bem- sucedido e bem- estar psicológico. In: NERI, A. L.; FREIRE, S. A. (Org.). E por falar em boa velhice. Campinas, SP: Papirus, 2000. p. 21-31.

FREIRE, S. A.; RESENDE, M. C. Sentido de vida e envelhecimento. In: NERI, A. L. (Org.). Maturidade e velhice: trajetórias individuais e socioculturais. Campinas: Papirus, 2001. p. 71-97.

GALLAGHER, E. N.; VELLA-BRODRICK, D. A. Social support and emotional intelligence as predictors of subjective well-being. Personality and Individual Differences, [S.1.], v. 44, p. 1551-1561, 2008. 
GOMES, M. S. A.; LESSA, J.; SÁ, R. N. de. O papel do idoso nas dinâmicas sociais de realização do ser no-mundo-com-o-outro. Revista Transdisciplinar de Gerontologia, v. 1, n. 1, p. 07-12, dez./maio 2006-2007.

GRIEP, R. H.; CHOR, D.; FAERSTEIN, E. Apoio social: confiabilidade teste-reteste de escala no estudo pró-saúde. Cadernos de Saúde Publica, Rio de Janeiro, v. 19, n. 2, p. 625-634, 2003.

GUEDEA, M. T. D. et al. Relação do bem-estar subjetivo, estratégias de enfrentamento e apoio social em idosos. Psicol. Reflex. Crit., Porto Alegre, v. 19, n. 2, p. 301-308, 2006.

JOIA, L. C.; RUIZ, T.; DONALISIO, M. R. Condições associadas ao grau de satisfação com a vida entre a população de idosos. Rev. Saúde Pública, São Paulo, v. 41, n. 1, p. 131-138, 2007.

KAROLY, P.; RUEHLMAN, L. S. Psychological "resilience” and its correlates in chronic pain: findings from a national community sample. Pain, [S.1.], v. 123, p. 90-97, 2006.

KRAUSE, N. Longitudinal study of social support and meaning in life. Psychology \& Aging, [S.1.], v. 22, n. 3, p. 456-469, 2007.

LARANJEIRA, C. A. S. J. Do vulnerável ser ao resiliente envelhecer: revisão de literatura. Psicologia: Teoria e Pesquisa, Brasília, v. 23, n. 3, p. 327-332, 2007.

MELLA, R. et al. Factores asociados al bienestar subjetivo en el adulto mayor. Psykhe, [S.1.], v.13, n. 1, p. 79-89, 2004.

NERI, A. L. Velhice e qualidade de vida na mulher. In: NERI, A. L. (Org.). Desenvolvimento e Envelhecimento. Campinas, SP: Papirus, 2001. p. 161-200.

NOGUEIRA, E. J. Rede de relações sociais: um estudo transversal com homens e mulheres pertencentes a três grupos etários. 2001. Tese (Doutorado em Educação)-Faculdade de Educação, UNICAMP, Campinas, SP, 2001.

OAKSFORD, K.; FRUDE, N.; CUDDIHY, R. Positive coping and stress-related psychological growth following lower limb amputation. Rehabilitation Psychology, [S.1.], v. 50, n. 3, 266-277, 2005.

OLIVEIRA, V. C. Vida de mulher: gênero, pobreza e saúde mental. 2007. Dissertação (Mestrado em Psicologia Clínica e Cultura)-Universidade de Brasília, Brasília, 2007.

PASSARELI, P. M.; SILVA, J. A. Psicologia positiva e o estudo do bem-estar subjetivo. Estudos de Psicologia, Campinas, v. 24, n. 4, p. 513-517, 2007. 
PESCE, R. et al. Risco e proteção: em busca de um equilíbrio promotor de resiliência. Psicologia: Teoria e Pesquisa, Brasília, v. 20, n. 2, p. 135-143, maio/ago. 2004.

PINHEIRO, D. P. N. A resiliência em discussão. Psicologia em Estudo, Maringá, v. 9, p. 67-75, 2004.

POLETTO, M. Resiliencia de crianças em contextos de desenvolvimento diversos: família e instituição. 2007. Dissertação (Mestrado em Psicologia)-Universidade Federal do Rio Grande do Sul, Porto Alegre, 2007.

RAMOS, M. P. Apoio Social e Saúde entre idosos. Sociologias, Porto Alegre, v. 4, n. 7, jan./jun. 2002.

RESENDE, M. C.; RABELO, D. F. Envelhecer com deficiência física: experiência com grupos educativos. Estudos Interdisciplinares sobre o Envelhecimento, [S.1.], v. 6, p. 41$51,2004$.

RESENDE, M. C. et al. Rede de relações sociais e satisfação com a vida de adultos e idosos. Psicol. Am. Lat., [S.1.], v. 5, n. 5, p. 1-20, 2006.

RESENDE, M. C. et al. Rede de relações e satisfação com a vida em pessoas com amputação de membros. Ciências \& Cognição, Rio de Janeiro, v. 10, p. 164-177, 2007.

RODRIGUES, M. S.; COHEN, S. Social Suport. Encyclopedia of Mental Health, v. 3, p. 535-544, 1998.

RYAN, R. M.; FREDERICK, C. M. On energy, personality and health: subjective vitality as a dynamic reflection of well-being. Journal of Personality, v. 65, n. 3, p. 259-565, September 1997.

RYFF, C. D. Happiness is everything, or is it? Explorations on the meaning of psychological well-being. Journal of Personality and Social Psychology, [S.1.], v. 57, n. 6, p. 1069-1081, 1989.

SILVA, I. et al. Efeitos do apoio social na qualidade de vida, controle metabólico e desenvolvimento de complicações crônicas em indivíduos com diabetes. Psicologia, Saúde e Doenças, Lisboa, v. 4, n. 1, p. 21-32, 2003.

SIQUEIRA, M. M. M. Construção e validação da Escala de Percepção de Suporte Social. Psicologia em Estudo, Maringá, v. 13, n. 2, p. 381-388, 2008.

SIROIS, F. M.; DAVIS, C. G.; MORGAN, M. Learning to live with what you can't rise above: control beliefs, symptom control, and adjustment to tinnitus. Health Psychology, [S.1.], v. 25, n. 1, p. 119-123, 2006. 
VERAS, R. Envelhecimento populacional contemporâneo: demandas, desafios e inovações. Revista Saúde Pública, São Paulo, v. 43, n. 3, p. 548-554, 2009.

YUNES, M. A. M. Psicologia positiva e resiliência: o foco no indivíduo e na família. Psicologia em Estudo, Maringá, v. 8, n. esp., p. 75-84, 2003.

YUNES, M. A. M.; SZYMANSKI, H. Resiliência: noção, conceitos afins e considerações críticas. In: TAVARES, J. (Org.). Resiliência e educação. São Paulo: Cortez, 2001. p. $13-42$.

Recebido em: agosto de 2009 Aceito em: setembro de 2010 
